University of Wollongong

Research Online

Faculty of Social Sciences - Papers (Archive) Faculty of Arts, Social Sciences \& Humanities

$1-1-2019$

Comparing neuropsychological performance in adults with obsessivecompulsive disorder, attention-deficit hyperactivity disorder and healthy controls: An online study

Olivia Winkworth

University of Wollongong

Susan J. Thomas

University of Wollongong, sthomas@uow.edu.au

Follow this and additional works at: https://ro.uow.edu.au/sspapers

Part of the Education Commons, and the Social and Behavioral Sciences Commons

Research Online is the open access institutional repository for the University of Wollongong. For further information contact the UOW Library: research-pubs@uow.edu.au 


\title{
Comparing neuropsychological performance in adults with obsessive-compulsive disorder, attention-deficit hyperactivity disorder and healthy controls: An online study
}

\author{
Abstract \\ Aims: Both obsessive-compulsive disorder (OCD) and adult attention deficit hyperactivity. disorder \\ (ADHD) are associated with neuropsychological underperformance, however few studies have directly \\ compared neuropsychological performance between individuals with OCD versus those with ADHD. \\ Additionally, previous studies have often included participants with comorbid conditions including \\ depression, which may confound results.
}

Method: Adults with existing diagnoses of OCD $(n=20)$ or ADHD $(n=71)$ without comorbid disorders, and controls $(n=63)$ completed online measures of symptoms of OCD, ADHD and depressive symptoms, and tasks assessing executive functions, working memory, inhibition and attention using an online cognitive testing platform. Analyses of variance and correlations were performed.

Results: Overall cognitive performance did not significantly differ between the OCD, ADHD and control participants. OCD and ADHD symptoms were inversely related to neuropsychological performance on tasks assessing attention and visuospatial working memory respectively. However, test performance was more frequently correlated with depressive than OCD or ADHD symptoms.

Conclusions: The results suggest that neuropsychological underperformance associated with OCD and ADHD may be related to the presence of comorbid disorders, such as depression, rather than disorderspecific phenomena, highlighting the importance of excluding participants with comorbid disorders in neuropsychological studies and targeting comorbidities in clinical contexts.

\section{Disciplines \\ Education | Social and Behavioral Sciences}

\section{Publication Details}

Winkworth, O. \& Thomas, S. J. (2019). Comparing neuropsychological performance in adults with obsessive-compulsive disorder, attention-deficit hyperactivity disorder and healthy controls: An online study. Journal of Obsessive-Compulsive and Related Disorders, 23 100477-1-100477-11. 


\section{Journal Pre-proof}

Comparing neuropsychological performance in adults with obsessive-compulsive disorder, attention-deficit hyperactivity disorder and healthy controls: An online study

Olivia Winkworth, Susan J. Thomas

PII: $\quad$ S2211-3649(19)30064-8

DOI: $\quad$ https://doi.org/10.1016/j.jocrd.2019.100477

Reference: JOCRD 100477

To appear in: Journal of Obsessive-Compulsive and Related Disorders

Received Date: 15 April 2019

Revised Date: 29 July 2019

Accepted Date: 9 September 2019

Please cite this article as: Winkworth O. \& Thomas S.J., Comparing neuropsychological performance in adults with obsessive-compulsive disorder, attention-deficit hyperactivity disorder and healthy controls: An online study, Journal of Obsessive-Compulsive and Related Disorders (2019), doi: https:// doi.org/10.1016/j.jocrd.2019.100477.

This is a PDF file of an article that has undergone enhancements after acceptance, such as the addition of a cover page and metadata, and formatting for readability, but it is not yet the definitive version of record. This version will undergo additional copyediting, typesetting and review before it is published in its final form, but we are providing this version to give early visibility of the article. Please note that, during the production process, errors may be discovered which could affect the content, and all legal disclaimers that apply to the journal pertain.

(C) 2019 Published by Elsevier Inc. 
Title page

Comparing Neuropsychological Performance in Adults with obsessivecompulsive disorder, attention-deficit hyperactivity disorder and healthy controls: An Online Study

\section{Authors}

Olivia Winkworth,

School of Psychology,

Faculty of Social Sciences,

University of Wollongong Australia

ow855@uowmail.edu.au

Susan J Thomas (corresponding author)

Graduate Medicine,

Faculty of Science, Medicine and Health \&

Illawarra Health and Medical Research Institute,

University of Wollongong,

NSW,

Australia 2522

sthomas@uow.edu.au

Telephone: +61242215928 
Title page

Comparing Neuropsychological Performance in Adults with obsessivecompulsive disorder, attention-deficit hyperactivity disorder and healthy controls: An Online Study 


\begin{abstract}
Aims: Both obsessive-compulsive disorder (OCD) and adult attention deficit hyperactivity disorder (ADHD) are associated with neuropsychological underperformance, however few studies have directly compared neuropsychological performance between individuals with OCD versus those with ADHD. Additionally, previous studies have often included participants with comorbid conditions including depression, which may confound results.
\end{abstract}

Method: Adults with existing diagnoses of OCD $(n=20)$ or ADHD $(n=71)$ without comorbid disorders, and controls $(n=63)$ completed online measures of symptoms of OCD, ADHD and depressive symptoms, and tasks assessing executive functions, working memory, inhibition and attention using an online cognitive testing platform. Analyses of variance and correlations were performed.

Results: Overall cognitive performance did not significantly differ between the OCD, ADHD and control participants. OCD and ADHD symptoms were inversely related to neuropsychological performance on tasks assessing attention and visuospatial working memory respectively. However, test performance was more frequently correlated with depressive than OCD or ADHD symptoms.

Conclusions: The results suggest that neuropsychological underperformance associated with OCD and ADHD may be related to the presence of comorbid disorders, such as depression, rather than disorder-specific phenomena, highlighting the importance of excluding participants with comorbid disorders in neuropsychological studies and targeting comorbidities in clinical contexts.

Keywords: OCD; ADHD; neuropsychological; cognition; executive function 
Obsessive-compulsive disorder (OCD) and attention deficit hyperactivity disorder (ADHD) are two common neuropsychiatric conditions, with adult estimated prevalence rates of 1.6-2.3\% for OCD (Kessler, Chiu et al., 2006; Ruscio, Stein, Chiu, \& Kessler, 2010) and approximately 3.4\% (range 1.2-7.3\%) for adult ADHD (Fayyad et al., 2007; Kessler, Adler, et al., 2006; Simon, Czobor, Bálint, Mészáros, \& Bitter, 2009). While OCD is characterised by obsessions and compulsions, ADHD is characterised by inattention and/or hyperactivity (American Psychiatric Association [APA], 2013). Moreover, OCD has been associated with increased activity within fronto-striatal and fronto-parietal networks (Harrison et al., 2009; Sakai et al., 2011), while ADHD has been associated with decreased activity in these networks (Kasparek, Theiner, \& Filova, 2015; Sidlauskaite, Sonuga-Barke, Roeyers, \& Wiersema, 2016). These contrasting clinical profiles have led to conclusions that the two disorders may lie on opposite ends of an impulsive-compulsive spectrum (Abramovitch, Dar, Hermesh, \& Schweiger, 2012; van den Heuvel et al., 2010). OCD is conceptualised to be at the compulsive end of the spectrum, being associated with planned behaviours or mental acts (compulsivity) carried out in order to avoid harm or distress arising from obsessions, and ADHD at the impulsive end of the spectrum, being associated with unplanned behaviours carried out regardless of their potential to cause harm (impulsivity). Both ends of the spectrum have been related to poor inhibition, suggesting that inhibitory difficulties may be a common issue across OCD and ADHD (Abramovitch et al., 2012; Moeller et al., 2001). Additionally, while the symptoms of OCD and ADHD are conceptualised as being at opposite ends of the spectrum, there are some similarities in symptoms reported. For example, intrusive and worrisome thoughts (Abramovitch \& Schweiger, 2009), and obsessive behaviour (Fullana et al., 2013) have been reported in individuals with ADHD.

Neuropsychology relates to the examination of specific cognitive abilities (e.g. executive functions, working memory inhibition, and attention) thought to be indicative of underlying 
brain function or dysfunction (Heilbronner, 2007). Poor performance on neuropsychological tasks is related to decreased functioning and quality of life in individuals diagnosed with psychiatric disorders (Brissos, Dias, \& Kapczinski, 2008; Cotrena, Branco, Shansis, \& Fonseca, 2016). Understanding the neuropsychology of OCD and ADHD is therefore important for formulating accurate conceptualisations and interventions. Given their contrasting diagnostic and neurobiological profiles, yet shared inability to inhibit behaviours or thoughts (APA, 2013; Fullana et al., 2013; Rubia, Cubillo, Woolley, Brammer, \& Smith, 2011), it is expected that individuals with OCD and ADHD should display both overlapping and distinct neuropsychological anomalies. However, there are some indications that individuals with these disorders display similar neuropsychological anomalies (Abramovitch et al., 2012; Abramovitch, Dar, Mittelman, \& Wilhelm, 2015), so further research is needed.

Most neuropsychological studies have compared a group with either OCD or ADHD to a group of healthy controls. Underperformance has been observed on tasks assessing executive functions (i.e. Wisconsin Card Sorting Task [WCST], Trail-Making Task B, and Tower of London Task) in individuals with OCD compared to controls (Abramovitch, Abramowitz, \& Mittelman, 2013; Abramovitch, Dar, Schweiger, \& Hermesh, 2011; Krishna et al., 2011; Shin, Lee, Kim, \& Kwon, 2014) and those with ADHD relative to controls (Boonstra, Oosterlaan, Sergeant, \& Buitelaar, 2005; Halleland, Haavik, \& Lundervold, 2012; Schreiber, Javorsky, Robinson, \& Stern, 2010). Similarly, both clinical groups display poorer performance than controls on tasks assessing verbal and visuospatial working memory (i.e. recognition tasks and n-back tasks; Abramovitch, Abramowitz, et al., 2013; Alderson, Kasper, Hudec, \& Patros, 2013; Kim, Liu, Glizer, Tannock, \& Woltering, 2014; Ko et al., 2013; Roopesh, Janardhan Reddy, \& Mukundan, 2013). Difficulties on tasks assessing inhibition (e.g. Stroop Task, Continuous Performance Task [CPT], and Go/No-Go Task) and attention (e.g. Stroop Task, CPT, Go/No-Go Task and forward span tasks) have also been noted in some studies of individuals with OCD 
(Abramovitch, Abramowitz, et al., 2013; Abramovitch \& Cooperman, 2015; Bannon, Gonsalvez and Croft, 2002; Penadés et al., 2007) and ADHD (Boonstra et al., 2005; Dobson-Patterson, O’Gorman, Chan, \& Shum, 2016; Johnson et al., 2001; Schoechlin \& Engel, 2005) relative to controls.

The overlapping performance anomalies observed in individuals with OCD and those with ADHD raises questions over the extent to which neuropsychological profiles are distinct or similar in these disorders (Abramovitch \& Schweiger, 2015). Direct comparisons of neuropsychological performance between individuals with adult OCD and ADHD may therefore help to determine this issue. To our knowledge, only one study has done this. In a pioneering study, Abramovitch et al. (2012) compared neuropsychological performance in adult males with OCD to those with ADHD. Findings indicated comparable performance in executive functions and inhibition, with poorer performance in the OCD compared to the ADHD group in attention and non-verbal memory. Both groups performed worse than controls. In this study 24 of 30 participants in the OCD group had comorbid mental disorders. Performance between those with and without comorbidity was compared and no statistically significant differences were found in this subgroup analyses. However, it is possible that subgroup analyses with small cell sizes may be underpowered to detect differences. Additionally, depressive symptoms were psychometrically measured in the OCD but not ADHD or control groups, and depressive symptoms were not included as a covariate in analyses. It may therefore be worth building on this work to compare performance in individuals without comorbidities, while statistically controlling for effects of subclinical depressive symptom severity.

Additionally, a prior study comparing neuropsychological performance in children was inconsistent, noting that children with ADHD performed poorer than those with OCD in executive functions and attention (Shin et al., 2008). Current comparative research is therefore 
limited and further research comparing individuals with OCD and ADHD is needed to ascertain the specific nature of their neuropsychological profiles.

Previous research of each disorder separately has provided significant insight into the neuropsychology of OCD and ADHD through its use of validated test batteries and screening measures. Nevertheless, there are some methodological limitations within these studies to be considered. Many studies either fail to exclude participants with comorbid disorders or control for them when analysing performance (Abramovitch et al., 2011; Alderson et al., 2013; Boonstra et al., 2005; Halleland et al., 2012; Schoechlin \& Engel, 2005; Shin et al., 2014). Depression is highly comorbid with OCD (Brakoulias et al., 2017; Quarantini et al., 2011) and ADHD (Anker, Bendiksen, \& Heir, 2018; Kessler et al., 2006) and is associated with similar profiles of neuropsychological underperformance to those reported in OCD and ADHD (Butters et al., 2011; Castaneda, Tuulio-Henriksson, Marttunen, Suvisaari, \& Lönnqvist, 2008; Elliott, 1998). There are indications that co-morbid depressive symptoms have artificially inflated executive deficit scores in some neuropsychological studies of OCD (Aycicegi, Dinn, Harris, \& Erkmen, 2003; Basso, Bornstein, Carona, \& Morton, 2001; Moritz et al., 2001), and that depressive symptoms may directly affect neuropsychological performance even in the absence of depression diagnoses (Moritz et al., 2001). Despite over 250 published studies examining neuropsychological performance in $\mathrm{OCD}$, there is considerable inconsistency in findings and a failure to identify a specific profile of neuropsychological underperformance in OCD (Abramovitch \& Cooperman, 2015). Accounting for depressive symptom severity and comparing between multiple psychiatric diagnostic groups are key methodological requirements to identify whether there are disorder-specific neuropsychological performance profiles (Abramovitch \& Cooperman, 2015).

Additionally, there is a lack of investigation of relationships between ADHD symptom severity and neuropsychological performance in comparative literature of OCD and ADHD. It is 
therefore a current gap in literature to assess whether severity of ADHD symptoms is correlated with aspects of neuropsychological performance.

Moreover, many studies have used all male samples (Abramovitch et al., 2012; Johnson et al., 2001; Ko et al., 2013; Krishna et al., 2011; Schoechlin \& Engel, 2005). ADHD symptoms can manifest differently within males and females (Fedele, Lefler, Hartung, \& Canu, 2012). Additionally, sex is an important determinant of health and wellbeing, and single-sex studies provide limited generalisability and understanding of health conditions across the sexes (Heidari et al., 2016). Samples of OCD and ADHD participants in neuropsychological studies have also been fairly small (Abramovitch et al., 2011; Dobson-Patterson et al., 2016; Johnson et al., 2001; Krishna et al., 2011; Penadés et al., 2007; Roopesh et al., 2013), a concern given that OCD and ADHD are heterogeneous conditions (Abramovitch, Dar, Mittelman, \& Schweiger, 2013; Dobson-Patterson et al., 2016). This may be because traditional face-to-face neuropsychological assessment, while considered reliable and valid (Germine et al., 2012), requires participants to travel to assessment centres, potentially limiting the sample sizes of previous studies (Abramovitch et al., 2012; Kraut et al., 2004; Reips, 2002). It is therefore worth exploring whether larger samples can potentially be recruited to studies through the use of new, online, technology which allows remote assessment of neuropsychological performance. While remote online batteries are being trialled with other clinical groups, to our knowledge they have yet to be assessed in OCD and ADHD.

A theoretical model of OCD was proposed by Abramovitch et al. (2012) in order to explain the neuropsychological performance of individuals with OCD, known as the Executive Overload Model (EOM). The model suggests that while people with OCD may share similar impairments with other disorders, such as ADHD, these impairments stem from disorderspecific phenomena. That is, impairments associated with OCD emerge at later stages due to a complex epiphenomenon associated with hyperactivated fronto-striatal networks. Conversely, 
impairments associated with ADHD may emerge earlier and are due to hypoactivated frontostriatal brain networks (Abramovitch et al., 2012).

However, people with other mental disorders also share similar neuropsychological underperformance to individuals with OCD and ADHD (Abramovitch \& Schweiger, 2015; Castaneda et al., 2008; Cuesta et al., 2017; Snyder, 2013). Therefore, suggesting that similar anomalies are caused by OCD or ADHD-specific phenomena may not be the most parsimonious explanation of the overlapping aspects of underperformance across the two disorders. There may, alternatively, be general deficits occurring across mental health diagnoses, leading to similar patterns of neuropsychological underperformance (Carter Leno et al., 2017; Thomas, Gonsalvez, \& Johnstone, 2014). Therefore, more research is needed to develop and evaluate the EOM model.

The current study aims to build on previous research in order to gain a greater understanding of neuropsychological performance in adults with OCD compared to those with ADHD, using an online neuropsychological test battery. The use of an online test battery may potentially enable access to larger samples of participants (Reips, 2002) while retaining similar reliability and validity to face-to-face assessment (Germine et al., 2012). Given that depressive symptoms are related to neuropsychological performance and frequently co-occur with OCD and ADHD, these will be measured and statistically controlled for within the current study, and only participants without diagnosed comorbidities will be recruited.

The current study will measure relationships between OCD and ADHD symptom severity and neuropsychological performance across groups. This information will be used to ascertain whether OCD and ADHD symptoms are related to specific aspects of neuropsychological performance, which may be used to evaluate the utility of the EOM as an appropriate conceptualisation of neuropsychological profiles observed in these disorders. The following hypotheses are proposed. 
1. Participants with OCD will display significantly higher levels of OCD symptoms relative to those with ADHD and controls. Those with ADHD will display significantly higher levels of ADHD symptoms compared to those with OCD and controls.

2. Both OCD and ADHD groups will display poorer performance on neuropsychological tasks compared to controls in aspects of set-shifting, response inhibition, working memory, attention and visuo-spatial working memory.

3. Symptoms of OCD and ADHD will be negatively correlated with neuropsychological performance. If the EOM is supported, there will be distinct relationships between disorderspecific symptoms and neuropsychological performance.

\section{Methods}

\subsection{Participants}

Inclusion criteria across groups required that participants be over the age of 18, without a diagnosed neurological disorder. Clinical participants were required to have a current diagnosis of adult ADHD or OCD from a healthcare professional and to be symptomatic, with no comorbid mental health conditions. Participants with OCD and ADHD were recruited through social media, internet support groups for these disorders and flyers around the university campus. Clinical participants were not excluded if they were taking medication, with the proviso that they had not taken stimulant medication in the preceding 12 hours. Both clinical groups included medicated and un-medicated participants (Table 1). Three participants with ADHD were taking Vyvanse. Because of the possibility of long-acting effects, analyses were run with and without these participants. The results were equivalent, hence it was decided to report the full sample results.

Control participants (controls) were required to have no significant past or present mental health problems and no diagnosed mental disorders. Controls were recruited online via advertisements on social media, flyers on campus, and through the university psychology 
student research participation scheme. Psychology students were offered course credits in return for participation in the study.

The initial sample consisted of 22 individuals with OCD, 81 individuals with ADHD, and 65 controls. After removing individuals missing over $20 \%$ of their data $(n=6)$ and those who did not fit study criteria $(n=8)$, a total of 20 individuals with OCD, 71 individuals with ADHD, and 63 controls were included.

Table 1

Medication Use Among Clinical Participants $(N=91)$

\begin{tabular}{lcc}
\hline & OCD & ADHD \\
& $(n=20)$ & $(n=71)$ \\
\cline { 2 - 3 } & $n(\%)$ & $n(\%)$ \\
\hline SSRIs & $4(20)$ & $2(2.82)$ \\
TCAs & $2(10)$ & $1(1.41)$ \\
Occasional benzodiazepines & $1(5)$ & $0(0.00)$ \\
Stimulants & $0(0.00)$ & $33(46.48)$ \\
NRIs & $0(0.00)$ & $1(1.41)$ \\
Combined medications & $3(15)$ & $3(4.23)$ \\
None & $10(50)$ & $31(43.66)$ \\
\hline
\end{tabular}

Note. SSRIs $=$ selective serotonin reuptake inhibitors; TCAs $=$ tricyclic antidepressants; NRIs $=$ norepinephrine reuptake inhibitors

\subsection{Materials}

Participants completed several online psychometric measures. Demographic information was collected, including age, gender, years of education, medical conditions and medication. Clinical participants were asked for the date of their mental health diagnosis and the type of healthcare professional who had made the diagnosis. All participants completed the Obsessive-Compulsive Inventory Revised (OCI-R; Foa et al., 2002) as a measure of OCD symptoms, the Adult ADHD Self-Report Scale v1.1 (ASRS; Adler et al., 2006) as a measure of ADHD symptoms, and the Patient Health Questionnaire-9 (PHQ-9; Kroenke, Spitzer, \& Williams, 2001) as a measure of depressive symptoms. Participants then completed four neuropsychological tasks powered by Cognition Lab (Berisoft Inc., 2018). All tasks were completed online on the participant's own computer. 


\subsubsection{Symptom Severity Scales}

\subsubsection{Obsessive-Compulsive Inventory Revised}

The OCI-R is an 18 -item shortened version of the 42 -item Obsessive-Compulsive Inventory designed to assess for symptoms of OCD (Foa et al., 2002). Using a five-point Likert scale, participants rated how much an experience bothered or distressed them over the past month. Responses ranged from "Not at all" (0 points) to "Extremely" (4 points). Higher scores were indicative of greater presence of OCD symptoms. The OCI-R has demonstrated good test-retest reliability in an online setting $(r=.85$; Moritz, Van Quaquebeke, Hauschildt, Jelinek, \& Gönner, 2012). It also displays good internal consistency, with Cronbach's alphas of .81 and .86 reported by Foa et al. (2002) and Moritz et al. (2012) respectively. Cronbach's alpha within the current study was comparable to previous findings $(\alpha=.90)$, suggesting good internal consistency.

\subsubsection{Adult ADHD Self-Report Scale v1.1}

The ASRS is an 18-item self-report version of the clinician-administered ADHD Rating Scale designed to assess for symptoms of adult ADHD (Adler et al., 2006). Participants rated how they had conducted themselves over the past six months using a 5-point Likert scale ranging from "Never" (0 points) to "Very Often" (4 points). Higher scores are indicative of a greater frequency, and in turn severity, of ADHD symptoms. The ASRS has shown good concurrent validity compared with the clinician-administered ADHD Rating Scale, with reported correlations of .84 and .72 identified in adult and adolescent populations respectively (Adler et al., 2006, 2012). Moreover, it has displayed high internal consistency, with reported Cronbach's alphas of .88 and .93 identified by Adler et al. (2006) and Adler et al. (2012) respectively. Cronbach's alpha within the current study was comparable to previous findings $(\alpha=.94)$, indicating good internal consistency. 


\subsubsection{Patient Health Questionnaire-9}

The PHQ-9 is a 9-item scale designed to assess for severity of depressive symptoms and disorders (Kroenke et al., 2001). Participants rated how often they had been bothered by each of the items over the past 2 weeks on a 4-point Likert scale ranging from "Not at all" ( 0 points) to "Nearly every day" (3 points). A higher score was indicative of greater severity of depressive symptoms.

High internal consistency has been noted for the PHQ-9, with a reported Cronbach's alpha coefficient of .80 in an online version $(\mathrm{Du}, \mathrm{Yu}, \mathrm{Ye}, \& \mathrm{Chen}, 2016)$ and .88 in a computerised version (Erbe, Eichert, Rietz, \& Ebert, 2016). Cronbach's alpha within the current study was comparable to these findings $(\alpha=.86)$, indicating good internal consistency. Good test-retest reliability has also been noted within an online setting (Du et al., 2016). Excellent concurrent validity $(r=.92)$ has also been noted between computerised and paper versions of the PHQ-9 (Erbe et al., 2016).

\subsubsection{Cognition Lab}

Cognition Lab is a web-based cognitive testing platform which hosts a number of neuropsychological tasks and test batteries. These are based on well-established neuropsychological tests, and the original PC-based system (ERTS) has been used by hundreds of universities globally for cognitive research (ERTSLab, 1999). The psychometric properties of these tests in a computerised setting have been found to be similar to those of the conventional neuropsychological tests on which they are based (Gualtieri \& Johnson, 2006). Due to the novelty of web-based cognitive testing, little research has been conducted using Cognition Lab's testing platform. However, initial findings suggest that it is a reliable means of cognitive assessment in the context of assessing clinical and healthy participants (Beringer, Charvet, Goldinger, \& Shaw, 2019; Shaw, Song, Charvet, Beringer, \& \& Waibel, 2016). These findings 
are supported by research investigating similar web-based testing platforms, which indicate that they hold comparable reliability and validity to laboratory-based testing (Germine et al., 2012; Hansen et al., 2015; Hansen, Lehn, Evensmoen, \& Håberg, 2016; Morrison, Simone, Ng, \& Hardy, 2015; Silverstein et al., 2007). The current study utilised four tests from Cognition Lab's library, selected to measure a number of performance areas repeatedly implicated in OCD and ADHD studies and identified by Abramovitch's (2012) comparative summary of neurobiological, neuropsychological, and phenomenological characteristics of OCD and ADHD as being of relevance to both conditions. These included set-shifting, response inhibition, working memory, attention and visuo-spatial working memory. Participants were provided with a set of standard instructions prior to completing each task, however, no practice trials are included. Each task took approximately 3-6 minutes to complete.

\subsubsection{Card Sorting Test}

This task is a computerised adaption of the traditional WCST, thought to measure setshifting ability. Participants were instructed to sort 105 cards based on one of three features (background, shape, number). Participants were not told the sorting rule, but were given feedback about whether their responses were correct or not. The sorting rule was changed every five to nine trials and participants were required to deduce from feedback that the rule for sorting had changed and switch their sorting strategies. Set-shifting ability was measured as number of perseverative errors. That is, continuing to adhere to a rule despite it having changed.

The standard WCST has displayed good test-retest reliability after a two-and-a-half-year delay within a clinical population, with a generalisability coefficient of .94 (Ozonoff, 1995). Similar computerised versions of the WCST also display good concurrent validity with the standard WCST (Steinmetz, Brunner, Loarer, \& Houssemand, 2010). 


\subsubsection{Donders Response Types (Go/No-Go Reaction)}

This task assessed response inhibition and sustained attention, both of which are relevant to the impulsive-compulsive spectrum. Across 44 trials, participants were instructed to respond as quickly as possible to a diamond-shaped "Go" stimulus in the centre of their screen by pressing a key using the index finger of their dominant hand. At the same time, participants were asked to ignore a square-shaped "No-Go" stimulus which appeared half of the time. Participants were provided with feedback when they incorrectly responded. Attentional performance was gauged using omission errors (not responding when required) while inhibitory performance was gauged using commission errors (responding when not required to).

Similar computerised versions of the Go/No-Go task have displayed good test-retest reliability as a measure of attention $(r=.79)$ and executive functioning $(r=.80)$ (Schweiger, Doniger, Dwolatzky, Jaffe, \& Simon, 2003). Good discriminant validity for the Go/No-Go task was also observed for both attention $(\mathrm{AUC}=.77)$ and executive functioning $(\mathrm{AUC}=.81$; Dwolatzky et al., 2003).

\subsubsection{Digital Memory Span}

This task assessed attention and verbal working memory. Participants were asked to memorise a series of digits (starting with a sequence of three digits) presented consecutively on their screen. Following this, they were asked to recall the digits in the order they were presented using the numeric keys on their keyboard. With each correctly recalled sequence, the number of digits the participant was required to memorise increased by one. After two consecutive errors, the task ended. In order to assess verbal working memory, participants performed the same task again, with the requirement that they recall the digits in reverse order. Performance was gauged as the highest number of correctly recalled digits. 
Traditional digit span tasks display good test-retest reliability after 6 weeks $(r=.65)$ and good internal consistency ( $\alpha=.81)$ as a measure of working memory (Waters \& Caplan, 2003). Web-based versions of the digit span task have displayed good concurrent validity with the traditional digit span task $(r=.49)$ (Silverstein et al., 2007) and good test-retest reliability for both forward $(r=.66)$ and backward $(r=.64)$ span (Feenstra, Murre, Vermeulen, Kieffer, \& Schagen, 2018).

\subsubsection{Spatial Memory Span}

This task measured attention and visuospatial working memory. Within this task, a marker moved across four squares located on the computer screen in a random order. Participants were asked to memorise and recall the order in which the marker travelled across the squares, using keys on their keyboard. After two consecutive errors, the task ended. In order to assess visuospatial working memory, the same task was performed with the requirement that participants recall the marker's locations in reverse order. Performance was gauged as highest number of correctly recalled locations.

The traditional version of the spatial span task has displayed good internal consistency, with a reported Cronbach's alpha of .81 (Pham \& Hasson, 2014). A web-based version has also displayed good concurrent with the standard version, with correlations $r=.48$ and $r=.55$ for forward and backward span respectively (Morrison et al., 2015). Likewise, good test re-retest reliability has been reported after 70 days for forward span $(r=.53)$ and backward span $(r=.51$; Morrison et al., 2015).

\subsection{Procedure}

This study was reviewed and approved by the university ethics committee. Participants accessed the study via an internet link and were given full information about the study and the 
requirements needed to participate in terms inclusion and exclusion criteria and computer requirements. After providing informed consent, participants completed the questionnaires and neuropsychological tasks in the above order on their own computer via Cognition Lab's online testing platform. The study took approximately 30-40 minutes to complete. Participants could take rests between the tasks.

\subsection{Statistical Analysis}

A power analysis for a one-way ANCOVA with 3 groups in $\mathrm{G}^{*}$ Power with an alpha of .05 , and a medium effect size $(f=.25)$ indicated that a sample size of 158 participants would provide .80 power. The Statistical Package for the Social Sciences (SPSS) Version 24 was used to analyse the data. Prior to analyses, all variables were tested for violations of assumptions. Where assumptions were significantly violated, non-parametric tests were run as confirmatory analyses. Preliminary analyses of variance (ANOVAs) and Chi-square analyses were conducted to examine between-group differences in demographic variables, and in depressive, OCD and ADHD symptoms (measured by the PHQ-9, OCI-R and ASRS respectively). Analyses of covariance (ANCOVAs) were conducted to compare neuropsychological performance between groups, while controlling for age and depressive symptoms. Where equality of variance assumptions were violated, Welch and Brown-Forsythe robust tests of equality of means were run as confirmatory analyses (Fan \& Hancock, 2012). Levene's test indicated that the homogeneity of variance assumption was violated only for OCD symptoms (OCI-R). Both the Welch and Brown-Forsythe tests were therefore performed and both gave the same results as the ANOVA. Relationships between neuropsychological performance, demographic variables and symptom severity measures (OCI-R; ASRS; PHQ-9) were examined using correlational analyses. Due to violations of normality and homoscedasticity within the data, Spearman's rho was used. 


\section{Results}

\subsection{Demographic Characteristics and Symptom Severity Measures}

Demographic characteristics (age, years of education, gender) and symptom severity scores (OCI-R; ASRS; PHQ-9) across study groups are reported in Table 2. The proportion of sexes did not differ significantly between groups, $\chi^{2}(4, N=154)=2.41, p=.66$.

Between-group ANOVAs indicated that there were statistically significant differences between groups for age $(p<.001)$, OCD symptoms (OCI-R) $(p<.001)$, ADHD symptoms (ASRS) $(p<.001)$, and depressive symptoms (PHQ-9) $(p=.004)$. However, no significant differences were observed between groups in years of education.

Post-hoc analyses using Tukey's HSD (using an $\alpha$ of .05) indicated that the ADHD group was significantly older than controls $(p<.001)$. However, no significant age differences were observed between the ADHD group and OCD group $(p=.067)$, nor between the OCD group and controls $(p=.797)$. In relation to OCD symptoms, the OCD group displayed significantly more OCD symptoms than the ADHD group $(p<.001)$ and controls $(p<.001)$, with no significant differences noted between the ADHD group and controls $(p=.222)$. Further investigation of ADHD symptoms indicated that the ADHD group displayed significantly greater ADHD symptoms than both the OCD group $(p<.001)$ and controls $(p<.001)$. The OCD group also displayed significantly more ADHD symptoms than controls $(p=.023)$. Finally, the OCD group displayed significantly greater depressive symptoms than controls $(p=.005)$. However, no significant differences in depressive symptoms were observed between the ADHD group and controls $(p=.081)$, nor between the OCD group and ADHD group $(p=.197)$. 
Table 2

Demographic Characteristics and Symptom Severity Across Study Groups $(N=154)$

\begin{tabular}{|c|c|c|c|c|c|c|c|c|c|c|}
\hline \multirow[b]{2}{*}{ Variable } & \multirow{2}{*}{$\begin{array}{c}\text { OCD } \\
(n=20) \\
M(S D)\end{array}$} & \multirow{2}{*}{$\begin{array}{c}\text { ADHD } \\
(n=71)\end{array}$} & \multirow{2}{*}{$\begin{array}{l}\begin{array}{c}\text { Controls } \\
(n=63)\end{array} \\
\mathrm{M}(\mathrm{SD})\end{array}$} & \multirow[b]{2}{*}{$F$} & \multicolumn{3}{|c|}{ Tukey's HSD Post-Hoc Analyser } & \multicolumn{3}{|c|}{ Cohen's $d$} \\
\hline & & & & & $\begin{array}{c}\text { OCD versı } \\
\text { Controls }\end{array}$ & $\begin{array}{c}\text { OCD versı } \\
\text { ADHD }\end{array}$ & $\begin{array}{c}\text { ADHD } \\
\text { versus } \\
\text { Controls }\end{array}$ & $\begin{array}{c}\text { OCD versı } \\
\text { Controls }\end{array}$ & $\begin{array}{c}\text { OCD versı } \\
\text { ADHD }\end{array}$ & $\begin{array}{c}\text { ADHD } \\
\text { versus } \\
\text { Controls }\end{array}$ \\
\hline Age $(\text { Years })^{\mathrm{a}}$ & $28.20(7.00)$ & $34.7(12.12)$ & $26.31(11.72)$ & $9.13 * * *$ & NS & NS & $* * *$ & 0.11 & 0.37 & 0.69 \\
\hline Years of education $^{b}$ & $16.70(3.96)$ & $16.00(3.78)$ & $15.55(2.77)$ & 0.90 & - & - & - & - & - & - \\
\hline \multicolumn{11}{|l|}{ Symptom measures } \\
\hline OCI-R ${ }^{b}$ & $34.35(3.33)$ & $20.30(10.33)$ & $17.03(11.12)$ & $17.88 * * *$ & $* * *$ & $* * *$ & NS & 0.97 & 0.80 & 0.27 \\
\hline $\mathrm{ASRS}^{\mathrm{b}}$ & $36.50(10.16)$ & $52.62(7.66)$ & $30.17(10.50)$ & $101.51 * * *$ & $*$ & $* * *$ & $* * *$ & 0.43 & 1.12 & 2.28 \\
\hline \multirow[t]{2}{*}{ PHQ-9 ${ }^{b}$} & $12.00(5.96)$ & $9.42(6.12)$ & $7.22(5.56)$ & $5.63 * * *$ & $* *$ & NS & NS & 0.52 & 0.28 & 0.35 \\
\hline & $\mathrm{n}(\%)$ & $\mathrm{n}(\%)$ & $\mathrm{N}(\%)$ & & & & & & & \\
\hline Gender & & & & 2.41 & - & - & - & - & - & - \\
\hline Female & $13(65.00)$ & $46(64.79)$ & $41(65.08)$ & & - & - & - & - & - & - \\
\hline Male & $7(35.00)$ & $23(32.39)$ & $22(34.92)$ & & - & - & - & - & - & - \\
\hline Other & $0(0.00)$ & $2(2.82)$ & $0(0.00)$ & & - & - & - & - & - & - \\
\hline
\end{tabular}

Note. OCI-R = Obsessive Compulsive Inventory-Revised; ASRS = Adult ADHD Self-Report Scale; PHQ-9 = Patient Health Questionnaire-9. ${ }^{*} p<.05,{ }^{* *} p<.01{ }^{* * *} p<.001 .^{\mathrm{a}} d f=2,145 .{ }^{\mathrm{b}} d f=2,151$. NS = not significant. 


\subsection{Analyses of Covariance (ANCOVAs)}

To examine whether neuropsychological performance differed between groups, one-way ANCOVAs were conducted comparing groups on each outcome measure of the neuropsychological test battery, controlling for age and depressive symptoms (PHQ-9). Means, standard deviations, and analysis of covariance results for the neuropsychological measures are displayed in Table 3. After controlling for the effects of age and depressive symptoms, there was a statistically significant difference between groups only for backward digit span scores $(p=$ .040). Levene's test for equality of variance was not significant for this variable $(p=.75)$, indicating that the assumption of homogeneity of variance was not violated and the result of the F-test could be relied upon even in the case of uneven group sizes (Fan \& Hancock, 2012). Posthoc analyses with pairwise comparisons for backwards digit span scores revealed that OCD participants exhibited significantly lower digit span scores than controls $(p=.033)$. However, no significant differences were observed between ADHD participants and controls $(p=.256)$, nor between OCD and ADHD participants $(p=.175)$. However, after controlling for multiple comparisons, using an alpha of .007 (.05 divided by seven comparisons), the between-group ANCOVA differences were not significant.

Age was significantly associated with go/no-go commission errors $(p=.032)$ and omission errors $(p=.006)$. However, age was not significantly related to any other outcome measures. Depressive symptoms were significantly associated with forward spatial span scores $(p=.007)$, but were unrelated to other outcome measures. 
Table 3: Means, Standard Deviations, and Analysis of Covariance Results for Each Neuropsychological Outcome Measure (N = 154)

\begin{tabular}{|c|c|c|c|c|c|c|c|c|c|}
\hline \multirow[b]{2}{*}{ Variable } & \multicolumn{2}{|c|}{$\begin{array}{c}\text { OCD } \\
(n=20)\end{array}$} & \multicolumn{2}{|c|}{$\begin{array}{l}\text { ADHD } \\
(n=71)\end{array}$} & \multicolumn{2}{|c|}{$\begin{array}{l}\text { Controls } \\
(n=63)\end{array}$} & \multirow[b]{2}{*}{$F(2,143)$} & \multirow[b]{2}{*}{$p$} & \multirow[b]{2}{*}{$\eta_{\mathrm{p}}^{2}$} \\
\hline & Mean & SD & Mean & SD & Mean & SD & & & \\
\hline CS perseveration errors & 12.00 & 12.53 & 10.76 & 8.60 & 9.63 & 8.33 & 0.49 & .615 & .01 \\
\hline Age (covariate) & - & - & - & - & - & - & 0.01 & .927 & .00 \\
\hline PHQ-9 score (covariate) & - & - & - & - & - & - & 1.58 & .211 & .01 \\
\hline GNG commission errors & 5.10 & 3.23 & 5.38 & 4.29 & 4.52 & 3.61 & 0.92 & .399 & .01 \\
\hline Age (covariate) & - & - & - & - & - & - & $4.71 *$ & .032 & .03 \\
\hline PHQ-9 score (covariate) & - & - & - & - & - & - & 3.60 & .060 & .03 \\
\hline GNG omission errors & 0.75 & 1.07 & 1.48 & 3.02 & 0.84 & 1.43 & 2.02 & .136 & .03 \\
\hline Age (covariate) & - & - & - & - & - & - & $7.90 * *$ & .006 & .05 \\
\hline PHQ-9 score (covariate) & - & - & - & - & - & - & 0.15 & .696 & .00 \\
\hline Forward digit span score & 7.45 & 1.76 & 7.04 & 1.69 & 7.19 & 1.03 & 0.51 & .604 & .01 \\
\hline Age (covariate) & - & - & & - & - & - & 0.05 & .822 & .00 \\
\hline PHQ-9 score (covariate) & - & - & - & - & - & - & 3.68 & .057 & .03 \\
\hline Backward digit span score & 4.75 & 2.29 & 5.68 & 2.11 & 6.22 & 2.39 & $3.30 *$ & .040 & .04 \\
\hline Age (covariate) & - & - & - & - & - & - & 1.69 & .196 & .01 \\
\hline PHQ-9 score (covariate) & - & - & - & - & - & - & 1.86 & .175 & .01 \\
\hline Forward spatial span score & 4.70 & 1.98 & 5.13 & 1.90 & 5.35 & 1.55 & 1.32 & .270 & .02 \\
\hline Age (covariate) & - & - & - & - & - & - & 0.85 & .357 & .01 \\
\hline PHQ-9 score (covariate) & - & - & - & - & - & - & $7.47 * *$ & .007 & .05 \\
\hline Backward spatial span score & 4.10 & 1.45 & 4.15 & 1.89 & 4.62 & 1.64 & 1.54 & .218 & .02 \\
\hline Age (covariate) & - & - & - & - & - & - & 2.45 & .120 & .02 \\
\hline PHQ-9 score (covariate) & - & - & - & - & - & - & 3.49 & .064 & .02 \\
\hline
\end{tabular}

Note. $\mathrm{CS}=$ card sorting; $\mathrm{GNG}=$ go/no-go.

$* p<.05 ; * * p .01$ 


\subsection{Correlations}

Correlations between variables across the three groups are presented in Table 4. There were significant negative correlations between OCI-R scores and forward spatial span scores, and between ASRS scores and backward spatial span scores (Table 4). A significant positive correlation was observed between the PHQ-9 and Go/No-Go commission errors, while significant negative correlations were observed between the PHQ-9 and backward digit span scores and forward spatial span scores.

Age correlated positively with ASRS scores (Table 4). Significant positive correlations were also observed between the symptom severity measures (OCI-R; ASRS; PHQ-9), indicating that individuals with high scores on one symptom measure were likely to have higher scores on other symptom measures. Years of education correlated positively with backwards digit span score, however, no significant correlations were observed between age and neuropsychological measures. Significant correlations were also observed between most neuropsychological outcome measures, indicating that higher performance on one task was linked to better performance on others (Table 4).

Correlations between variables for each group separately are presented in Table 5. Using the $\mathrm{G}^{*}$ Power statistical tool, version 3.1.9.4, to achieve a statistical power of $80 \%$ with significance at $p<.05$, for two-tailed correlations with a medium effect size (.03), a total of 84 participants is required. Our power calculations therefore show that separate correlations in each of the groups are underpowered, and therefore may not provide reliable results (Button et al., 2013). However, we are including the separate group correlations for comparison with previous studies, which often present correlations by group, even with small samples. 
Table 4

Spearman's rho $\left(r_{\mathrm{s}}\right)$ Correlations Between Study Variables, Across Groups $(N=154)$

\begin{tabular}{|c|c|c|c|c|c|c|c|c|c|c|c|}
\hline Variable & 1 & 2 & 3 & 4 & 5 & 6 & 7 & 8 & 9 & 10 & 11 \\
\hline 1. Age & - & & & & & & & & & & \\
\hline 2. Years of education & $-.34 * *$ & - & & & & & & & & & \\
\hline 3. OCI-R score & -.08 & -.16 & - & & & & & & & & \\
\hline 4. ASRS score & $.20 *$ & -.04 & $.31 * *$ & - & & & & & & & \\
\hline 5. PHQ-9 score & -.12 & -.15 & $.58^{* *}$ & $.43^{* *}$ & - & & & & & & \\
\hline 6. CS perseveration errors & .05 & -.06 & .07 & .09 & .09 & - & & & & & \\
\hline 7. GNG commission errors & -.14 & -.15 & .05 & .13 & $.26^{* *}$ & $.25^{* *}$ & - & & & & \\
\hline 8. GNG omission errors & .10 & -.16 & .08 & .10 & .13 & $.28 * *$ & $.20 *$ & - & & & \\
\hline 9. Forward digit span score & -.02 & .06 & .01 & .01 & -.10 & -.09 & -.07 & -.02 & - & & \\
\hline 10. Backward digit span score & .13 & $.24 * *$ & -.10 & -.15 & $-.21 * *$ & $.28 * *$ & $.30 * *$ & $-.23 * *$ & $.20 *$ & - & \\
\hline 11. Forward spatial span score & -.09 & .14 & $-.17 *$ & -.09 & $-.19 *$ & $-.29 * *$ & -.16 & $-.31 * *$ & $.23 * *$ & $.32 * *$ & - \\
\hline 12. Backward spatial span score & -.14 & $.18^{*}$ & -.06 & $-.16^{*}$ & -.15 & $-.25 * *$ & $-.18^{*}$ & $-.34 * *$ & .08 & $.40 * *$ & $.50 * *$ \\
\hline
\end{tabular}

Note. $* p<.05$ (two-tailed); $* * p<.01$ (two-tailed).

OCI-R = Obsessive-Compulsive Inventory-Revised; ASRS = Adult ADHD Self-Report Scale; CS = card sorting; GNG = go/no-go 
Table 5: Spearman's rho $\left(r_{\mathrm{s}}\right)$ Correlations Between Study Variables, by Group

\begin{tabular}{|c|c|c|c|c|c|c|c|c|c|c|c|}
\hline Healthy Control Group $(n=63)$ & 1 & 2 & 3 & 4 & 5 & 6 & 7 & 8 & 9 & 10 & 11 \\
\hline \multicolumn{12}{|l|}{ 1. Age } \\
\hline 2. Years of education & $0.59 * *$ & & & & & & & & & & \\
\hline 3. OCI-R score & -0.13 & -0.11 & & & & & & & & & \\
\hline 4. ASRS score & -0.22 & -0.14 & .49 ** & & & & & & & & \\
\hline 5. PHQ-9 score & -0.18 & -0.10 & $.62^{* *}$ & $.72 * *$ & & & & & & & \\
\hline 6. CS perseveration errors & 0.04 & 0.14 & 0.12 & 0.08 & -0.01 & & & & & & \\
\hline 7. GNG commission errors & -0.15 & -0.14 & 0.07 & 0.11 & 0.17 & 0.24 & & & & & \\
\hline 8. GNG omission errors & 0.07 & -0.07 & 0.07 & 0.05 & -0.04 & 0.13 & $.44 * *$ & & & & \\
\hline 9. Forward digit span score & -0.07 & -0.05 & 0.18 & $.26 *$ & 0.11 & 0.07 & 0.02 & 0.18 & & & \\
\hline 10. Backward digit span score & $0.45 * *$ & $0.34 * *$ & 0.05 & -0.12 & -0.12 & -0.17 & $-.32 *$ & $-.25 *$ & 0.00 & & \\
\hline 11. Forward spatial span score & -0.23 & -0.08 & 0.04 & -0.08 & -0.12 & $-.28 *$ & -0.22 & -0.24 & 0.07 & 0.1 & \\
\hline 12. Backward spatial span score & -0.12 & -0.05 & 0.10 & 0.04 & 0.01 & -0.07 & -0.06 & $-.30^{*}$ & -0.11 & $.32 *$ & $.41 * *$ \\
\hline OCD Group $(n=20)$ & 1 & 2 & 3 & 4 & 5 & 6 & 7 & 8 & 9 & 10 & 11 \\
\hline 1. Age & - & & & & & & & & & & \\
\hline 2. Years of education & $.45^{*}$ & & & & & & & & & & \\
\hline 3. OCI-R score & 0.07 & -0.29 & & & & & & & & & \\
\hline 4. ASRS score & -0.29 & -0.25 & $.71 * *$ & & & & & & & & \\
\hline 5. PHQ-9 score & -0.19 & -0.27 & $.68 * *$ & $.80^{* *}$ & & & & & & & \\
\hline 6. CS perseveration errors & 0.23 & -0.20 & 0.15 & 0.05 & 0.13 & & & & & & \\
\hline 7. GNG commission errors & -0.32 & -0.38 & 0.18 & 0.27 & 0.42 & 0.25 & & & & & \\
\hline 8. GNG omission errors & 0.25 & 0.16 & 0.43 & 0.20 & 0.16 & 0.35 & -0.20 & & & & \\
\hline 9. Forward digit span score & 0.23 & 0.14 & -0.18 & $-.48 *$ & $-.61 * *$ & $-.47 *$ & -0.36 & -0.09 & & & \\
\hline 10. Backward digit span score & -0.03 & 0.08 & -0.33 & -0.25 & -0.44 & -0.27 & -0.08 & -0.17 & 0.40 & & \\
\hline 11. Forward spatial span score & 0.21 & 0.34 & -0.35 & -0.17 & -0.16 & -0.31 & -0.18 & -0.30 & 0.16 & 0.43 & \\
\hline 12. Backward spatial span score & 0.12 & $.52 *$ & $-.45^{*}$ & -0.35 & -0.31 & $-.49 *$ & -0.28 & $-.48 *$ & 0.30 & 0.10 & $.58 * *$ \\
\hline ADHD Group $(n=71)$ & 1 & 2 & 3 & 4 & 5 & 6 & 7 & 8 & 9 & 10 & 11 \\
\hline 1. Age & - & & & & & & & & & & \\
\hline 2. Years of education & 0.14 & & & & & & & & & & \\
\hline 3. OCI-R score & $-.266^{*}$ & $-.32 * *$ & & & & & & & & & \\
\hline 4. ASRS score & -0.03 & -0.05 & $.25^{*}$ & & & & & & & & \\
\hline 5. PHQ-9 score & -0.23 & $-.24 *$ & $.38 * *$ & $0.31 * *$ & & & & & & & \\
\hline 6. CS perseveration errors & 0.02 & -0.18 & -0.02 & 0.02 & 0.15 & & & & & & \\
\hline 7. GNG commission errors & -0.20 & -0.12 & -0.05 & 0.02 & $.29 *$ & $.26^{*}$ & & & & & \\
\hline 8. GNG omission errors & 0.03 & $-.29 *$ & 0.04 & 0.00 & $.23 *$ & $.37 * *$ & 0.08 & & & & \\
\hline 9. Forward digit span score & -0.05 & 0.11 & -0.09 & 0.19 & -0.14 & -0.10 & -0.06 & -0.13 & & & \\
\hline 10. Backward digit span score & 0.05 & $.30 *$ & -0.01 & -0.03 & -0.10 & $-.33 * *$ & $-.30 *$ & -0.23 & $.28 *$ & & \\
\hline 11. Forward spatial span score & 0.00 & $.25 *$ & $-.28 *$ & -0.11 & -0.23 & $-.31 * *$ & -0.08 & $-.36 * *$ & $.33^{* *}$ & $.41 * *$ & \\
\hline 12. Backward spatial span score & -0.15 & $.27 *$ & 0.00 & -0.06 & -0.15 & $-.34 * *$ & -0.20 & $-.31 * *$ & 0.11 & $.50 * *$ & $.54 * *$ \\
\hline
\end{tabular}

Note. ${ }^{*} p<.05$ (two-tailed); $* * p<.01$ (two-tailed). OCI-R = Obsessive-Compulsive Inventory-Revised; ASRS = Adult ADHD Self-Report Scale; CS = card sorting; GNG = go/no-go 


\section{Discussion}

The current study aimed to gain a more accurate understanding of the overlapping and distinct neuropsychological performance characteristics associated with adult OCD and ADHD. It also aimed to investigate relationships between symptoms of OCD and ADHD and neuropsychological performance, so as to further evaluate the EOM as a conceptualisation of neuropsychological performance within these disorders. Additionally, we sought to assess the feasibility of an online approach to neuropsychological assessment in these disorders, with the use of relatively new technology.

As hypothesised, the OCD group exhibited significantly higher levels of OCD symptoms compared to the ADHD group and controls, while the ADHD group displayed significantly greater levels of ADHD symptoms compared to the OCD group and controls. These results suggest that clinical groups displayed symptom profiles reflective of their respective disorders. Thus, any similarities in performance across groups cannot be attributed to overlapping symptom profiles.

Contrary to our predictions, overall performance in the neuropsychological test battery was similar across the OCD, ADHD and control groups. However, the OCD group performed worse than controls on the backward digit span task. This is consistent with some research indicating poorer performance on verbal working memory tasks in participants with OCD (Abramovitch, Abramowitz, et al., 2013; Abramovitch et al., 2011; Roopesh et al., 2013). However, it contradicts other research which has failed to find poorer verbal working memory performance (Harkin \& Kessler, 2011; Krishna et al., 2011) or found small effect sizes for verbal working memory compared to other domains (Abramovitch, Abramowitz, et al., 2013) in individuals with OCD. Therefore, in the current study, individuals with OCD and ADHD did not display neuropsychological underperformance compared to controls, save for verbal working memory within OCD. However, given that the current finding is not robust enough to survive a 
correction for multiple comparisons, and no other underperformance was found in the OCD or ADHD groups, overall the results are interpreted as indicating largely similar performance across the groups.

Neuropsychological research in OCD is notoriously highly inconsistent, with the magnitude of underperformance being small-medium and highly heterogeneous where found (Abramovitch \& Cooperman, 2015). Additionally, multiple studies report no performance differences between OCD and controls (e.g. Abbruzzese, Ferri, \& Scarone, 1995; BlairSimpson et al., 2006; Kurt, Yildirim \& Topçuoğlu, 2017; Whitney, Fastenau, Evans, \& Lysaker, 2004) and several others report no differences in executive functioning between individuals with OCD and controls (reviewed in Aycicegi et al., 2003).

Similarly, studies of ADHD have found inconsistent and often null results (reviewed in Weyandt et al., 2017). Factors such as symptom severity, symptom subtypes, comorbid disorders, the state or trait nature of impairment (Abramovitch \& Cooperman, 2015) and motivational factors (Moritz, Hauschildt, Saathoff, \& Jelinek, 2017) may all contribute to heterogeneity of results. Additionally, many studies fail to correct alpha levels for multiple comparisons, which may inflate type 1 errors and reduce reproducibility.

In the current study, the similar performance between clinical groups and controls may have occurred due to the study's exclusion of individuals with known comorbid mental disorders and statistical control for the influence of subclinical depressive symptoms. Given that previous studies have failed to exclude or control for comorbid disorders (Abramovitch et al., 2011; Alderson et al., 2013; Boonstra et al., 2005; Halleland et al., 2012; Schoechlin \& Engel, 2005; Shin et al., 2014), it is possible that comorbid disorders impacted neuropsychological performance in these studies. Thus, when this influence is removed, people with OCD and ADHD may not experience significantly poorer neuropsychological performance compared to controls. This explanation is consistent with Krishna et al. (2011), who found that 
neuropsychological performance did not differ significantly from controls within a sample of non-depressed individuals with OCD, save for the Tower of London task. It also supports the findings of Moritz et al. (2001), who investigated a sample of OCD participants with comorbid depression and found that depressive symptoms were more closely related to neuropsychological performance than OCD symptoms within this sample. However, although we excluded participants with known comorbidities, it is possible that some participants in the current study were experiencing comorbid disorders without being aware of it. Thus, further online neuropsychological research would ideally include a thorough semi-structured interview to screen for all major DSM disorders.

We sought to evaluate the EOM which is one of the few theoretical models to address neuropsychological performance across OCD and ADHD. Contrary to hypotheses, individuals with OCD and ADHD did not display distinct performances on neuropsychological tasks, therefore the results did not substantiate that overlapping neuropsychological performance within OCD and ADHD occurs due to distinct processes within each disorder, as posited by the EOM (Abramovitch et al., 2012). OCD and ADHD are heterogeneous conditions. It is therefore possible that participants in the current study happened to be relatively free from neuropsychological abnormalities. Further research which does identify underperformance is needed to investigate the nature of this across diagnoses. We recruited symptomatic participants with diagnoses of either OCD or ADHD from a healthcare professional. We did not conduct clinical interviews with participants to confirm current diagnoses. Our symptom severity analysis using valid psychometric self-report tools, however, showed that the clinical groups differed in the predicted ways in terms of having significantly higher symptoms of their disorder than the healthy controls, therefore the largely similar performance between groups is not likely due to mild clinical presentations. It therefore remains a possibility that the similar performance across groups may be better explained by the absence of comorbid disorders in participants in 
the current study. Some researchers have suggested that neuropsychological underperformance observed within OCD and other mental disorders occur due to the presence of common deficits, not disorder-specific phenomena (Carter Leno et al., 2017; Thomas et al., 2014). Because psychiatric disorders, such as depression, often co-occur with OCD and ADHD, it is possible that overlapping profiles within OCD and ADHD occur due to the presence of common deficits associated with similar comorbid disorders.

Correlations indicated that as OCD and ADHD symptom severity increased, performance on neuropsychological tasks decreased. Significant correlations were observed between OCD symptoms and forward spatial span scores, and ADHD symptoms and backward spatial span scores. The significant correlations provide some support for the EOM, suggesting that attentional performance may be related to OCD-specific phenomena, while visuospatial working memory performance may be related to ADHD-specific phenomena (Abramovitch et al., 2012). These results support research noting attentional and visuospatial working memory impairments within OCD and ADHD respectively (Abramovitch, Abramowitz, et al., 2013; Abramovitch et al., 2011; Alderson et al., 2013; Greisberg \& McKay, 2003; Kasparek et al., 2015; Kim et al., 2014; Seidman, 2006; van Ewijk et al., 2015). The results suggest that further research correlating specific types of symptoms with neuropsychological performance may be of interest.

Alternatively, poorer performance may primarily be related to common deficits observed across mental disorders (Carter Leno et al., 2017; Thomas et al., 2014). The current study noted a greater number of correlations between depressive symptoms and neuropsychological performance. Similar findings were also noted by Basso et al. (2001), Moritz et al. (2001) and Moritz et al. (2005). These results suggest that neuropsychological profiles within OCD and ADHD may be more closely related to common deficits associated with comorbid conditions, such as depression, rather than disorder-specific phenomena. Thus, while some neuropsychological underperformance may be related to OCD and ADHD-specific phenomena, 
underperformance may be subtle and not significant when experienced without comorbid disorders.

We also evaluated the potential utility of online neuropsychological testing as a means to recruit participants more broadly, as neuropsychological testing studies often have limited sample sizes due to the need for participants to travel to a testing site. We found that the current method was successful in recruiting healthy participants and those with ADHD diagnoses more successfully than those with diagnoses of OCD. Epidemiological research indicates that approximately $63 \%$ of individuals meeting criteria for a diagnoses of OCD in their lifetime also meet lifetime criteria for a mood disorder (Ruscio, Stein, Chiu, \& Kessler, 2010), with similar levels of comorbidity between ADHD and major depression (Kessler et al., 2005), so it is not likely that excluding those with comorbid depression led to lower recruitment rates solely in the OCD group. It may be more difficult to recruit people with OCD due to its generally lower prevalence relative to ADHD in the community. Our research group also found in previous studies that recruiting participants with OCD was far slower than participants with panic disorder, a more prevalent disorder. This factor may possibly contribute to the generally small sample sizes seen in OCD neuropsychological research, and the inclusion of participants with co-morbidities. Alternatively, people with OCD may volunteer for research at lower rates due to other, unknown, reasons. Nevertheless online cognitive testing has the potential to reach participants globally, and future online studies of OCD may be more successful in achieving larger samples if multi-site recruitment through OCD organisations is employed and longer time scales are planned.

Additionally, although ADHD shows a higher male-to-female odds ratio (Kessler, Chiu, et al., 2006), the current study received more female than male volunteers in the ADHD group. Larger proportions of women than men have been noted in adult ADHD patient groups, attributed to help-seeking or recognition bias (Kessler, Chiu, et al., 2006). This may be 
attributable to the fact that childhood referrals are usually initiated by parents or teachers and may be in response to externalising symptoms which are more common in males, whereas in adulthood self-referrals are common. Women with ADHD have more internalising problems than men, which may account for the higher rate of self-referrals in adulthood and the more balanced gender ratio in adult samples (Gómez-Benito, Van de Vijver, Balluerka, \& Caterino, 2019; Simon, Czobor, Bálint, Mészáros, \& Bitter, 2009).

\subsection{Limitations and Future Research}

Several limitations with the current study should be acknowledged. Firstly, the OCD group was relatively small because of a lower response rate from individuals with OCD to the study, precluding symptom subgroup analyses and indicating a need for future investigation with a larger clinical group. Overall the performance between groups was very similar, which did not suggest that marginal power was obscuring the ability to detect significant differences between groups. In future it may be necessary to plan longer-term and co-ordinated strategies to recruit participants with OCD, who may be slower to recruit, possibly due to the lower prevalence relative to other conditions.

The online test battery utilised is relatively new and as yet norms have not been published, however the digit span results are consistent with well-established norms (e.g. Orsini et al., 1987). Additionally, our three-group design allowed us to make conclusions based on the relative performance between the groups. The reliability and validity of the current test battery is yet to be established, although it is based on well-established neuropsychological tests which have been widely used in similar computerised batteries. Future research is required using different test batteries. The participants were self-selected and responded to advertisements in internet support groups, so it is possible that they are not representative of larger clinical populations. Previous neuropsychological studies may have invited participants from those 
attending treatment clinics. This may also introduce biases, as those may represent only the most severely affected by OCD or ADHD. Further research is needed to compare different types of participants in the neuropsychological tests.

We recruited participants with clinical diagnoses from health care professionals, and also assessed symptom severity using valid self-report psychometric tools. Future studies should seek to employ a comprehensive composite interview to confirm diagnoses and to screen for and exclude other DSM diagnoses. While the psychometric symptom measures showed the expected differences between diagnostic groups, it is possible that some individuals in the current study had been misdiagnosed by a health care professional. Performing semi-structured interviews is more challenging in an online method than in face-to-face testing, however it is possible. Additionally, it may be helpful to assess language proficiency and adequate vision in future studies.

Finally, medication use was not an exclusion criteria within the current study, except for stimulant medication within the last 12 hours. It is possible that medication may have affected the results of the clinical participants, improving their performance to be similar to controls, however, the symptom profiles showed that the participants were currently experiencing significantly higher levels of symptoms of their respective disorders, suggesting that the lack of neuropsychological differences was not due to mild or absent symptoms of OCD or ADHD. Previous research suggests that stimulant medication may have little effect on neuropsychological performance (reviewed in Weyandt et al., 2017), however research is still inconclusive and future research comparing medicated with non-medicated participants is needed.

Nonetheless, it is hoped that the study can contribute new information about a novel approach to assessing neuropsychological performance which can serve as a building block to future studies. Online neuropsychological test batteries are increasingly being used to expand 
research into a wide range of clinical conditions. Prospective studies could further investigate links between comorbid disorders or symptoms and neuropsychological performance within adults with OCD and ADHD, and to compare the performance of clinical groups with and without comorbidity. Meta-analyses indicate that neuropsychological performance differences, where found, in OCD are small-medium, may not be clinically significant, and are also found in a large number of mental disorders (Abramovitch, Abramowitz, et al., 2013), therefore more work is needed to understand how they relate to specific clinical symptoms. Theoretical models such as the EOM can inform, and be informed by, such research.

\subsection{Implications}

The current study found little evidence of neuropsychological impairment in OCD or ADHD when excluding participants with known comorbidities and controlling for severity of subclinical depressive symptoms. Poor neuropsychological performance may therefore not be intrinsic to each disorder's aetiology and maintenance, but may be indicative of other comorbid symptoms or disorders, highlighting the importance of targeting comorbid conditions in interventions for OCD and ADHD. Nevertheless, due to inconsistencies in research, further, large scale, research is required in order to confirm the role of comorbid disorders in the neuropsychology of these conditions. Online neuropsychological test batteries may be promising in future studies. The current study also highlights the importance of excluding participants with comorbid disorders, or controlling for these disorders within research investigating neuropsychological profiles of OCD and ADHD.

\subsection{Conclusions}

The current study found similar performance in an online neuropsychological test battery in participants with OCD or ADHD without comorbidities and healthy controls. The significant 


\section{Journal Pre-proof}

correlations provide some small support for the EOM (Abramovitch et al., 2012), suggesting that attentional performance may be related to OCD-specific phenomena, while visuospatial working memory performance may be related to ADHD-specific phenomena. However, depressive symptoms were also related to performance. This pattern of results suggests there may be disorder-specific links to performance in specific neuropsychological domains, however it is important to control for depressive symptoms as these are also related to performance. 


\section{References}

Abramovitch, A., Abramowitz, J. S., \& Mittelman, A. (2013). The neuropsychology of adult obsessivecompulsive disorder: A meta-analysis. Clinical Psychology Review, 33, 1163-1171. https://doi.org/10.1016/j.cpr.2013.09.004

Abramovitch, A., \& Cooperman, A. (2015). The cognitive neuropsychology of obsessive-compulsive disorder: A critical review. Journal of Obsessive-Compulsive and Related Disorders, 5, 24-36. https://doi.org/10.1016/j.jocrd.2015.01.002

Abramovitch, A., Dar, R., Hermesh, H., \& Schweiger, A. (2012).Comparative neuropsychology of adult obsessive-compulsive disorder and attention deficit/hyperactivity disorder: Implications for a novel executive overload model of OCD. Journal of Neuropsychology, 6, 161-191. https://doi.org/10.1111/j.1748-6653.2011.02021.x

Abramovitch, A., Dar, R., Mittelman, A., \& Schweiger, A. (2013). Don't judge a book by its cover: ADHD-like symptoms in obsessive compulsive disorder. Journal of Obsessive-Compulsive and Related Disorders, 2, 53-61. https://doi.org/10.1016/j.jocrd.2012.09.001

Abramovitch, A., Dar, R., Mittelman, A., \& Wilhelm, S. (2015). Comorbidity between attention deficit/hyperactivity disorder and obsessive-compulsive disorder across the lifespan: A systematic and critical review. Harvard Review of Psychiatry, 23, 245-262. https://doi.org/10.1097/HRP.0000000000000050

Abramovitch, A., Dar, R., Schweiger, A., \& Hermesh, H. (2011). Neuropsychological impairments and their association with obsessive-compulsive symptom severity in obsessive-compulsive disorder. Archives of Clinical Neuropsychology, 26, 364-376. https://doi.org/10.1093/arclin/acr022

Abramovitch, A., \& Schweiger, A. (2009). Unwanted intrusive and worrisome thoughts in adults with attention deficitlhyperactivity disorder. Psychiatry Research, 168, 230-233.Abramovitch, A., \& Schweiger, A. (2015). Misuse of cognitive neuropsychology in psychiatry research: The intoxicating appeal of neo-reductionism. Behaviour Therapist, 38, 187-191. 
Adler, L. A., Shaw, D. M., Spencer, T. J., Newcorn, J. H., Hammerness, P., Sitt, D. J., \& Faraone, S. V. (2012). Preliminary examination of the reliability and concurrent validity of the AttentionDeficit/Hyperactivity Disorder Self-Report Scale v1.1 Symptom Checklist to rate symptoms of attention-deficit/hyperactivity disorder in adolescents. Journal of Child and Adolescent Psychopharmacology, 22, 238-244. https://doi.org/10.1089/cap.2011.0062

Adler, L. A., Spencer, T., Faraone, S. V., Kessler, R. C., Howes, M. J., Biederman, J., \& Secnik, K. (2006). Validity of pilot adult ADHD Self-Report Scale (ASRS) to rate adult ADHD symptoms. Annals of Clinical Psychiatry, 18, 145-148. https://doi.org/10.1080/10401230600801077

Alderson, M. R., Kasper, L. J., Hudec, K. L., \& Patros, C. H. G. (2013). Attention-deficit/hyperactivity disorder (ADHD) and working memory in adults: A meta-analytic review. Neuropsychology, 27, 287-302. https://doi.org/10.1037/a0032371

American Psychiatric Association. (2013). Diagnostic and statistical manual of mental disorders (5th ed.). Arlington, VA: American Psychiatric Publishing.

Anker, E., Bendiksen, B., \& Heir, T. (2018). Comorbid psychiatric disorders in a clinical sample of adults with ADHD, and associations with education, work and social characteristics: A crosssectional study. BMJ Open, 8. https://doi.org/10.1136/bmjopen-2017-019700

Aycicegi, A., Dinn, W. M., Harris, C. L., \& Erkmen, H. (2003). Neuropsychological function in obsessive-compulsive disorder: effects of comorbid conditions on task performance. European Psychiatry, 18(5), 241-248.

Bannon, S., Gonsalvez, C. J., Croft, R. J., \& Boyce, P. M. (2002). Response inhibition deficits in obsessive-compulsive disorder. Psychiatry research, 110(2), 165-174.

Basso, M. R., Bornstein, R. a, Carona, F., \& Morton, R. (2001). Depression accounts for executive function deficits in obsessive-compulsive disorder. Neuropsychiatry, Neuropsychology, and Behavioral Neurology, 14, 241-245. Retrieved from http://www.ncbi.nlm.nih.gov/pubmed/11725218 
Beringer, J., Charvet, L., Goldinger, S. D., \& Shaw, M. (2019). Using Cognition Lab to bridge between 'in-lab' and lab-external studies. Paper presented at the TEAP 2019: Tagung Experimentell Arbeitender Psychologen, London Metropolitan University, London, United Kingdom.

Boonstra, A. M., Oosterlaan, J., Sergeant, J. A., \& Buitelaar, J. K. (2005). Executive functioning in adult ADHD: A meta-analytic review. Psychological Medicine, 35, 1097-1108. https://doi.org/10.1017/S003329170500499X

Brakoulias, V., Starcevic, V., Belloch, A., Brown, C., Ferrao, Y. A., Fontenelle, L. F., \& Viswasam, K. (2017). Comorbidity, age of onset and suicidality in obsessive-compulsive disorder (OCD): An international collaboration. Comprehensive Psychiatry, 76, 79-86. https://doi.org/10.1016/j.comppsych.2017.04.002

Brissos, S., Dias, V. V., \& Kapczinski, F. (2008). Cognitive performance and quality of life in bipolar disorder. The Canadian Journal of Psychiatry, 53, 517-524. https://doi.org/10.1177/070674370805300806

Butters, M. A., Bhalla, R. K., Andreescu, C., Wetherell, J. L., Mantella, R., Begley, A. E., \& Lenze, E. J. (2011). Changes in neuropsychological functioning following treatment for late-life generalised anxiety disorder. The British Journal of Psychiatry: The Journal of Mental Science, 199, 211-218. https://doi.org/10.1192/bjp.bp.110.090217

Button, K. S., Ioannidis, J. P., Mokrysz, C., Nosek, B. A., Flint, J., Robinson, E. S., \& Munafò, M. (2013). Power failure: why small sample size undermines the reliability of neuroscience. Nature Reviews Neuroscience, 14, 365.

Carter Leno, V., Chandler, S., White, P., Pickles, A., Baird, G., Hobson, C., \& Simonoff, E. (2017). Testing the specificity of executive functioning impairments in adolescents with ADHD, ODD/CD and ASD. European Child and Adolescent Psychiatry, 27, 1-10. https://doi.org/10.1007/s00787-017-1089-5

Castaneda, A. E., Tuulio-Henriksson, A., Marttunen, M., Suvisaari, J., \& Lönnqvist, J. (2008). A review 
on cognitive impairments in depressive and anxiety disorders with a focus on young adults. Journal of Affective Disorders, 106, 1-27. https://doi.org/10.1016/j.jad.2007.06.006

Cotrena, C., Branco, L. D., Shansis, F. M., \& Fonseca, R. P. (2016). Executive function impairments in depression and bipolar disorder: association with functional impairment and quality of life. Journal of Affective Disorders, 190, 744-753. http://dx.doi.org/10.1016/j.jad.2015.11.007.

Cuesta, M. J., Moreno-Izco, L., Ribeiro, M., Lo’́pez-Ilundain, J. M., Lecumberri, P., Cabada, T., \& Peralta, V. (2017). Motor abnormalities and cognitive impairment in first-episode psychosis patients, their unaffected siblings and healthy controls. Schizophrenia Research, 200, 50-55. https://doi.org/10.1016/j.schres.2017.10.035

Dobson-Patterson, R., O’Gorman, J. G., Chan, R. C. K., \& Shum, D. H. K. (2016). ADHD subtypes and neuropsychological performance in an adult sample. Research in Developmental Disabilities, 55, 55-63. https://doi.org/10.1016/j.ridd.2016.03.013

Du, N., Yu, K., Ye, Y., \& Chen, S. (2016). Validity study of Patient Health Questionnaire-9 items for Internet screening in depression among Chinese university students, 9, 1-5. https://doi.org/10.1111/appy.12266

Dwolatzky, T., Whitehead, V., Doniger, G. M., Simon, E. S., Schweiger, A., Jaffe, D., \& Chertkow, H. (2003). Validity of novel computerised cognitive battery for mild cognitive impairment. BMC Geriatrics, 3, 1-12. https://doi.org/10.1186/1471-2318-3-4

Elliott, R. (1998). The neuropsychological profile in unipolar depression. Trends in Cognitive Sciences, 2, 447-484. https://doi.org/10.1016/S1364-6613(98)01235-2

Erbe, D., Eichert, H.-C., Rietz, C., \& Ebert, D. (2016). Interformat reliability of the patient health questionnaire: Validation of the computerised version of the PHQ-9. Internet Interventions, 5, 14. https://doi.org/10.1016/j.invent.2016.06.006

Fan, W., \& Hancock, G. R. (2012). Robust means modeling: An alternative for hypothesis testing of independent means under variance heterogeneity and nonnormality. Journal of Educational 
Behavioral Statistics, 37(1), 137-156.

Farias, S. T., Harrell, E., Neumann, C., \& Houtz, A. (2003). The relationship between neuropsychological performance and daily functioning in individuals with Alzheimer's disease: ecological validity of neuropsychological tests. Archives of Clinical Neuropsychology, 18, 655672. https://doi.org/10.1016/s0887-6177(02)00159-2

Fayyad, J., De Graaf, R., Kessler, R., Alonso, J., Angermeyer, M., Demyttenaere, K., \& Lepine, J. P. (2007). Cross-national prevalence and correlates of adult attention-deficit hyperactivity disorder. The British Journal of Psychiatry, 190, 402-409.

Fedele, D. A., Lefler, E. K., Hartung, C. M., \& Canu, W. H. (2012). Sex differences in the manifestation of ADHD in emerging adults. Journal of Attention Disorders, 16, 109-117. https://doi.org/10.1177/1087054710374596

Feenstra, H. E. M., Murre, J. M. J., Vermeulen, I. E., Kieffer, J. M., \& Schagen, S. B. (2018). Reliability and validity of a self-administered tool for online neuropsychological testing: The Amsterdam Cognition Scan. Journal of Clinical and Experimental Neuropsychology, 40(3), 253-273. https://doi.org/10.1080/13803395.2017.1339017

Foa, E. B., Huppert, J. D., Leiberg, S., Langner, R., Kichic, R., Hajcak, G., \& Salkovskis, P. M. (2002). The Obsessive-Complusive Inventory: Development and validation of a short version. Psychological Assessment, 14, 485-495. https://doi.org/10.1037//1040-3590.14.4.485

Germine, L., Nakayama, K., Duchaine, B. C., Chabris, C. F., Chatterjee, G., \& Wilmer, J. B. (2012). Is the Web as good as the lab? Comparable performance from Web and lab in cognitive/perceptual experiments. Psychonomic Bulletin and Review, 19, 847-857. https://doi.org/doi:10.3758/s13423-012-0296-9

Greisberg, S., \& McKay, D. (2003). Neuropsychology of obsessive-compulsive disorder: a review and treatment implications. Clin Psychol Rev, 23, 95-9117. https://doi.org/10.1016/S02727358(02)00232-5 
Halleland, H. B., Haavik, J., \& Lundervold, A. J. (2012). Set-shifting in adults with ADHD. Journal of the International Neuropsychological Society, 18, 728-737.

https://doi.org/10.1017/S1355617712000355

Hansen, T. I., Haferstrom, E. C. D., Brunner, J. F., Lehn, H., Ivar, T., Haferstrom, E. C. D., \& Lehn, H. (2015). Initial validation of a web-based self-administered neuropsychological test battery for older adults and seniors Initial validation of a web-based self-administered neuropsychological test battery for older adults and seniors. Journal of Clinical and Experimental Neuropsychology, 37, 581-594. https://doi.org/10.1080/13803395.2015.1038220

Hansen, T. I., Lehn, H., Evensmoen, H. R., \& Håberg, A. K. (2016). Initial assessment of reliability of a self-administered web-based neuropsychological test battery. Computers in Human Behavior, 63, 91-97. https://doi.org/10.1016/j.chb.2016.05.025

Harkin, B., \& Kessler, K. (2011). The role of working memory in compulsive checking and OCD: A systematic classification of 58 experimental findings. Clinical Psychology Review, 31, 10041021. https://doi.org/10.1016/j.cpr.2011.06.004

Harrison, B. J., Soriano-Mas, C., Pujol, J., Ortiz, H., López-Solà, M., Hernández-Ribas, R., \& Pantelis, C. (2009). Altered corticostriatal functional connectivity in obsessive-compulsive disorder. Archives of General Psychiatry, 66, 1189-1200. Retrieved from https://www.library.uow.edu.au/index.html

Heidari, S., Babor, T. F., De Castro, P., Tort, S., \& Curno, M. (2016). Sex and gender equity in research: rationale for the SAGER guidelines and recommended use. Research Integrity and Peer Review, 1, 2.

Heilbronner, R. L. (2007). American Academy of Clinical Neuropsychology (AACN) practice guidelines for neuropsychological assessment and consultation. Clinical Neuropsychologist, 21, 209-231. doi:10.1080/13825580601025932

Johnson, D., Epstein, J. N., Waird, L. R., Latham, P. K., Voronin, K. E., \& Anton, R. F. (2001). 
Neuropsychological performance deficits in adults with attention deficit/hyperactivity disorder. Archives of Clinical Neuropsychology, 16, 587-604. https://doi.org/10.1016/S08876177(00)00070-6

Kasparek, T., Theiner, P., \& Filova, A. (2015). Neurobiology of ADHD from childhood to adulthood: Findings of imaging methods. Journal of Attention Disorders, 19, 931-943. https://doi.org/10.1177/1087054713505322

Kessler, R. C., Chiu, W. T., Demler, O., \& Walters, E. E. (2005). Prevalence, severity, and comorbidity of 12-month DSM-IV disorders in the National Comorbidity Survey Replication. Archives of General Psychiatry, 62(6), 617-627.

Kessler, R. C., Chiu, W. T., Jin, R., Ruscio, A. M., Shear, K., \& Walters, E. E. (2006). The epidemiology of panic attacks, panic disorder, and agoraphobia in the national comorbidity survey replication. Archives of General Psychiatry, 63, 415-424. https://doi.org/10.1001/archpsyc.63.4.415

Kim, S., Liu, Z., Glizer, D., Tannock, R., \& Woltering, S. (2014). Adult ADHD and working memory: Neural evidence of impaired encoding. Clinical Neurophysiology, 125, 1596-1603. https://doi.org/10.1016/j.clinph.2013.12.094

Ko, C. H., Yen, J. Y., Yen, C. F., Chen, C. S., Lin, W. C., Wang, P. W., \& Liu, G. C. (2013). Brain activation deficit in increased-load working memory tasks among adults with ADHD using fMRI. European Archives of Psychiatry and Clinical Neuroscience, 263, 561-573. https://doi.org/10.1007/s00406-013-0407-2

Kraut, R., Olson, J., Banaji, M., Bruckman, A., Cohen, J., \& Couper, M. (2004). Psychological research online: Report of the Board of Scientific Affairs' advisory group on the conduct of research on the internet. American Psychologist, 59, 105-117. https://doi.org/10.1037/0003-066X.59.2.105

Krishna, R., Udupa, S., George, C. M., Kumar, K. J., Viswanath, B., Kandavel, T., \& Reddy, Y. C. J. (2011). Neuropsychological performance in OCD: A study in medication-naïve patients. 
Progress in Neuro-Psychopharmacology and Biological Psychiatry, 35, 1969-1976. https://doi.org/10.1016/j.pnpbp.2011.09.009

Kroenke, K., Spitzer, R. L., \& Williams, J. B. W. (2001). The PHQ-9: Validity of a brief depression severity measure. Journal of General Internal Medicine, 16(9), 606-613. https://doi.org/10.1046/j.1525-1497.2001.016009606.x

Kurt, E., Yildirim, E., \& Topçuoğlu, V. (2017). Executive Functions of Obsessive Compulsive Disorder and Panic Disorder Patients in Comparison to Healty Controls. Archives of Neuropsychiatry, 54, 312-317. doi:10.5152/npa.2016.14872

Mathes, B. M., Morabito, D. M., \& Schmidt, N. B. (2019). Epidemiological and clinical gender differences in OCD. Current Psychiatry Reports, 21, 1-7. https://doi.org/10.1007/s11920-019$1015-2$

Moeller, F. G., Barratt, E. S., Dougherty, D. M., Schmitz, J. M., \& Swann, A. C. (2001).Psychiatric aspects of impulsivity. American Journal of Psychiatry, 158, 1783-1793. doi:10.1176/appi.ajp.158.11.1783

Moritz, S., Birkner, C., Kloss, M., Jacobsen, D., Fricke, S., Böthern, A. \& Hand, I. (2001). Impact of comorbid depressive symptoms on neuropsychological performance in obsessive-compulsive disorder. Journal of Abnormal Psychology, 110, 653-657. http://dx.doi.org/10.1037/0021$\underline{843 X .110 .4 .653}$

Moritz, S., Kloss, M., Jacobsen, D., Kellner, M., Andresen, B., Fricke, S., \& Hand, I. (2005). Extent, profile and specificity of visuospatial impairment in obsessive-compulsive disorder (OCD). Journal of Clinical and Experimental Neuropsychology, 27, 795-814. https://doi.org/10.1080/13803390490918480

Moritz, S., Van Quaquebeke, N., Hauschildt, M., Jelinek, L., \& Gönner, S. (2012). Good news for allegedly bad studies. Assessment of psychometric properties may help to elucidate deception in online studies on OCD. Journal of Obsessive-Compulsive and Related Disorders, 1, 331-335. 
https://doi.org/10.1016/j.jocrd.2012.07.001

Morrison, G. E., Simone, C. M., Ng, N. F., \& Hardy, J. L. (2015). Reliability and validity of the NeuroCognitive Performance Test, a web-based neuropsychological assessment. Frontiers in Psychology, 6, 1-15. https://doi.org/10.3389/fpsyg.2015.01652

Orsini, A., Grossi, D., Capitani, E., Laiacona, M., Papagno, C., \& Vallar, G. (1987). Verbal and spatial immediate memory span: normative data from 1355 adults and 1112 children. The Italian Journal of Neurological Sciences, 8, 537-548.

Ozonoff, S. (1995). Reliability and validity of the Wisconsin Card Sorting Test in studies of autism. Neuropsychology, 9, 491-500. https://doi.org/10.1037/0894-4105.9.4.491

Penadés, R., Catalán, R., Rubia, K., Andrés, S., Salamero, M., \& Gastó, C. (2007). Impaired response inhibition in obsessive compulsive disorder. European Psychiatry, 22, 404-410. https://doi.org/10.1016/j.eurpsy.2006.05.001

Pham, A. V., \& Hasson, R. M. (2014). Verbal and visuospatial working memory as predictors of children's reading ability. Archives of Clinical Neuropsychology, 29(5), 467-477. https://doi.org/10.1093/arclin/acu024

Quarantini, L. C., Torres, A. R., Sampaio, A. S., Fossaluza, V., Mathis, M. A. De, Do Rosário, M. C., \& Koenen, K. C. (2011). Comorbid major depression in obsessive-compulsive disorder patients. Comprehensive Psychiatry, 52, 386-393. https://doi.org/10.1016/j.comppsych.2010.09.006 Reips, U.-D. (2002). Standards for Internet-based experimenting. Experimental Psychology, 49, 243256. https://doi.org/10.1027//1618-3169.49.4.243

Roopesh, B. N., Janardhan Reddy, Y. C., \& Mukundan, C. R. (2013). Neuropsychological deficits in drug naïve, non-depressed obsessive-compulsive disorder patients. Asian Journal of Psychiatry, 6, 162-170. https://doi.org/10.1016/j.ajp.2012.10.003

Rubia, K., Cubillo, A., Woolley, J., Brammer, M. J., \& Smith, A. (2011). Disorder-specific dysfunctions in patients with attention-deficit/hyperactivity disorder compared to patients with obsessive- 
compulsive disorder during interference inhibition and attention allocation. Human Brain Mapping, 32, 601-611. https://doi.org/10.1002/hbm.21048

Ruscio, A. M., Stein, D. J., Chiu, W. T., \& Kessler, R. C. (2010). The epidemiology of obsessivecompulsive disorder in the National Comorbidity Survey Replication. Molecular Psychiatry, 15, 53-63. https://doi.org/10.1038/mp.2008.94

Sakai, Y., Narumoto, J., Nishida, S., Nakamae, T., Yamada, K., Nishimura, T., \& Fukui, K. (2011). Corticostriatal functional connectivity in non-medicated patients with obsessive-compulsive disorder. European Psychiatry, 26, 463-469. https://doi.org/10.1016/j.eurpsy.2010.09.005

Schoechlin, C., \& Engel, R. R. (2005). Neuropsychological performance in adult attention-deficit hyperactivity disorder: Meta-analysis of empirical data. Archives of Clinical Neuropsychology, 20, 727-744. https://doi.org/10.1016/j.acn.2005.04.005

Schreiber, H. E., Javorsky, D. J., Robinson, J. E., \& Stern, R. A. (2010). Rey-Osterrieth Complex Figure performance in adults with attention deficit hyperactivity disorder: A validation study of the Boston Qualitative Scoring System, 13, 37-41. https://doi.org/10.1076/1385-4046(199911)13

Schweiger, A., Doniger, G. M., Dwolatzky, T., Jaffe, D., \& Simon, E. S. (2003). Reliability of a novel computerized neuropsychological battery for mild cognitive impairment. Neuropsychologica, 1 , 407-413. https://doi.org/10.1186/1471-2318-3-4

Seidman, L. J. (2006). Neuropsychological functioning in people with ADHD across the lifespan. Clinical Psychology Review, 26, 466-485. https://doi.org/10.1016/j.cpr.2006.01.004

Shaw, M., Song, G., Charvet, L., Beringer, J., \& \& Waibel, U. (2016). Optimising the mobile clinical trial: Data collection through a web-based platform in telemedicine protocol. Boca Raton, FL.

Shin, M.-S., Choi, H., Kim, H., Hwang, J.-W., Kim, B.-N., \& Cho, S.-C. (2008). A study of neuropsychological deficit in children with obsessive-compulsive disorder. European Psychiatry, 23, 512-520. https://doi.org/10.1016/j.eurpsy.2008.03.010

Shin, N. Y., Lee, T. Y., Kim, E., \& Kwon, J. S. (2014). Cognitive functioning in obsessive-compulsive 
disorder: A meta-analysis. Psychological Medicine, 44, 1121-1130. https://doi.org/10.1017/S0033291713001803

Sidlauskaite, J., Sonuga-Barke, E., Roeyers, H., \& Wiersema, J. R. (2016). Altered intrinsic organisation of brain networks implicated in attentional processes in adult attentiondeficit/hyperactivity disorder: a resting-state study of attention, default mode and salience network connectivity. European Archives of Psychiatry and Clinical Neuroscience, 266, 349357. https://doi.org/10.1007/s00406-015-0630-0

Silverstein, S. M., Berten, S., Olson, P., Paul, R., Williams, L. M., Cooper, N., \& Gordon, E. (2007). Development and validation of a World-Wide Web-based neurocognitive assessment battery: WebNeuro. Behavior Research Methods, 39, 940-949. Retrieved from http://ovidsp.ovid.com/ovidweb.cgi?T=JS\&PAGE=reference \&D=psyc5\&NEWS=N\&AN=2007 $-19283-030$

Simon, V., Czobor, P., Bálint, S., Mészáros, Á., \& Bitter, I. (2009). Prevalence and correlates of adult attention-deficit hyperactivity disorder: Meta-analysis. British Journal of Psychiatry, 194, 204211. https://doi.org/10.1192/bjp.bp.107.048827

Snyder, H. R. (2013). Major depressive disorder is associated with broad impairments on neuropsychological measures of executive function: A meta-analysis and review. Psychological Bulletin, 139, 81-132. https://doi.org/10.1037/a0028727

Steinmetz, J. P., Brunner, M., Loarer, E., \& Houssemand, C. (2010). Incomplete psychometric equivalence of scores obtained on the manual and the computer version of the Wisconsin Card Sorting Test? Psychological Assessment, 22, 199-202. https://doi.org/10.1037/a0017661

Thomas, S. J., Gonsalvez, C. J., \& Johnstone, S. J. (2014). How specific are inhibitory deficits to obsessive-compulsive disorder? A neurophysiological comparison with panic disorder. Clinical Neurophysiology, 125, 463-475. https://doi.org/10.1016/j.clinph.2013.08.018

van den Heuvel, O. A., van der Werf, Y. D., Verhoef, K. M. W., de Wit, S., Berendse, H. W., Wolters, 


\section{Journal Pre-proof}

E. C., \& Groenewegen, H. J. (2010). Frontal-striatal abnormalities underlying behaviours in the compulsive-impulsive spectrum. Journal of the Neurological Sciences, 289, 55-59. https://doi.org/10.1016/j.jns.2009.08.043

van Ewijk, H., Weeda, W. D., Heslenfeld, D. J., Luman, M., Hartman, C. A., Hoekstra, P. J., \& Oosterlaan, J. (2015). Neural correlates of visuospatial working memory in attentiondeficit/hyperactivity disorder and healthy controls. Psychiatry Research - Neuroimaging, 233, 233-242. https://doi.org/10.1016/j.pscychresns.2015.07.003

Waters, G. S., \& Caplan, D. (2003). The reliability and stability of verbal working memory measures. Behavior Research Methods, Instruments, and Computers, 35(4), 550-564. https://doi.org/10.3758/BF03195534

Weyandt, L. L., Oster, D. R., Gudmundsdottir, B. G., DuPaul, G. J., \& Anastopoulos, A. D. (2017). Neuropsychological functioning in college students with and without ADHD. Neuropsychology, 31,160 . 


\section{Highlights}

Few studies have compared neuropsychological performance in OCD and adult ADHD, and previous studies have included participants with comorbid diagnoses.

Participants with OCD or ADHD without comorbidity performed similarly to controls in an online cognitive battery.

The results highlight the importance of excluding those with comorbid conditions when investigating neuropsychological performance in OCD. 


\section{Conflict of interest}

The authors have no conflicts of interest. 